\title{
Synthesis of Fused Indoline-Cyclobutanone Derivatives via an Intramolecular [2+2] Cycloaddition
}

\author{
Rifahath M. Neyyappadath, ${ }^{[a]}$ Mark D. Greenhalgh, ${ }^{[a]}$ David B. Cordes, ${ }^{[a]}$ Alexandra M. Z. Slawin, ${ }^{[a]}$ and \\ Andrew D. Smith*[a]
}

Abstract: A serendipitously-discovered process for the synthesis of heterocyclic products containing a novel fused indolinecyclobutanone ring system is reported. This process is believed to take place through in situ generation of a ketene intermediate, followed by intramolecular [2+2] cycloaddition with a pendant enamide. The formation of a ketene intermediate in this process is significant as the reaction conditions employed are analogous to those commonly used in tertiary amine Lewis base catalysis, where the potential intermediacy of ketenes is an important consideration that is often overlooked.

\section{Introduction}

Nitrogen-containing heterocycles constitute a privileged class of organic compounds, due to their prevalence within natural products and bioactive compounds. ${ }^{[1]}$ The importance of nitrogen-containing heterocycles in pharmaceuticals is highlighted by the fact that $59 \%$ of all FDA-approved smallmolecule drugs contain at least one nitrogen heterocycle. ${ }^{[1 b]}$ On average, $28 \%$ of all new small-molecule drugs approved each year also feature a new ring system, ${ }^{[1]}$ compounding the importance of developing methodologies that provide access to novel heterocyclic ring systems. Of particular interest are ring systems that contain $\mathrm{sp}^{3}$-hybidized carbons that can open up new vectors to explore 3D chemical space. ${ }^{[1 b-d, 2]}$

$\mathrm{C}(1)$-Ammonium enolate catalysis has been widely utilized for the diastereo- and enantioselective synthesis of carbo- and heterocyclic compounds. ${ }^{[3]}$ In 2001, Romo introduced an intramolecular aldol-lactonization protocol, using a cinchona alkaloid-derived catalyst $\mathbf{3}$, for the synthesis of enantioenriched bicyclic $\beta$-lactones 4 (Scheme 1a). ${ }^{[4]}$ This transformation was proposed to proceed via the key $\mathrm{C}(1)$-ammonium enolate intermediate 8 (Scheme 1b), which was formed following functionalization of the carboxylic acid of substrate 1 using Mukaiyama's reagent $2 .^{[5]}$ Although the generation of ketenes from carboxylic acids following functionalization with Mukaiyama's reagent 2 has been reported, ${ }^{[6]}$ the high enantioselectivity obtained in this protocol suggested that either formation of (C1)-ammonium enolate $\mathbf{8}$ was achieved without the intermediacy of a ketene 7 (Scheme $1 \mathrm{~b}$, Path $\mathbf{A}$ ), or that the ketene intermediate 7 was trapped by the tertiary amine catalyst 3 significantly faster than the rate of [2+2] cycloaddition with the pendant aldehyde to give racemic $\beta$-lactone $( \pm$ )-4 (Scheme $1 \mathrm{~b}$, Path B). The scope of this intramolecular aldol-lactonization protocol has been extended for the synthesis of various carbocycles and oxygen-containing heterocycles ${ }^{[7]}$ and applied in numerous natural product syntheses; ${ }^{[8]}$ however to date there have only been two applications of intramolecular aldollactonization for the synthesis of enantioenriched nitrogencontaining heterocycles. ${ }^{[9]}$

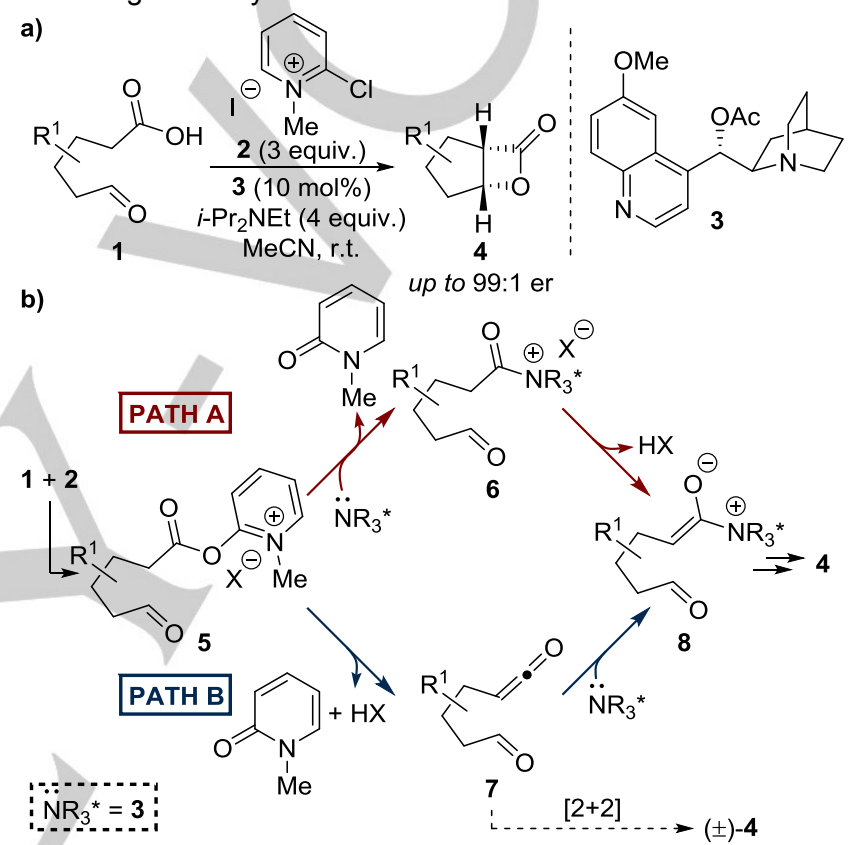

Scheme 1. Cinchona alkaloid-catalyzed aldol-lactonization

Our group subsequently extended the utility of $\mathrm{C}(1)$-ammonium enolate catalysis through the development of isothioureacatalyzed intramolecular Michael addition-lactonization protocols for the enantio- and diastereoselective synthesis of carbocyclic and heterocyclic products 12 (Scheme 2a). ${ }^{[10]}$ In these methodologies, optimal yields were obtained when pivaloyl chloride $\mathbf{1 0}$ was used for the in situ conversion of the carboxylic acid to a mixed anhydride. Application of this method for the synthesis of nitrogen-containing heterocycles has again remained notably under-developed, with only two examples disclosed to date. ${ }^{[11]}$ In the method reported for the synthesis of pyrrolidines $14,{ }^{[11 a]}$ isolation of the requisite enone-acid substrates proved inefficient and therefore a telescoped procedure was adopted, which involved sequential ozonolysis, Wittig olefination and isothiourea-catalyzed Michael additionlactonization (Scheme 2b).

[a] Dr R. M. Neyyappadath, Dr M. D. Greenhalgh, Dr D. B. Cordes Prof. A. M. Z. Slawin, Prof. A. D. Smith

EaStCHEM, School of Chemistry, University of St Andrews, St Andrews, Fife, KY16 9ST, UK.

E-mail: ads10@st-andrews.ac.uk

http://chemistry.st-andrews.ac.uk/staff/ads/group

Supporting information for this article is given via a link at the end of the document. 
<smiles>[R1]C=C(CCO)C(=O)C=CC=CC([R])=O</smiles>

$\mathrm{X}=\mathrm{O}, \mathrm{CH}_{2} ; \mathrm{n}=0,1$

$$
\text { ii) } \mathrm{Ph}-\underset{\mathrm{i} \mathrm{Pr}_{2} \mathrm{NEt}(>3 \text { equiv.) }}{\stackrel{\mathrm{N}}{\longrightarrow} \mathrm{N} / \mathrm{HCl}}
$$

$t-\mathrm{BuCOCl} 10$ (> 1 equiv.

$11(5-20 \mathrm{~mol} \%)$

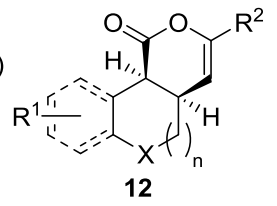

up to $99: 1$ er b)

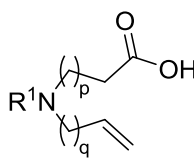

$$
\begin{aligned}
& 13 \\
& p=1, q=1 \\
& \text { or } p=0, q=2 \\
& \text { vi) } \mathrm{Ph} \\
& 11 \text { (0.1-5 mol\%) } \\
& \text { v) } \mathrm{MeOH}
\end{aligned}
$$

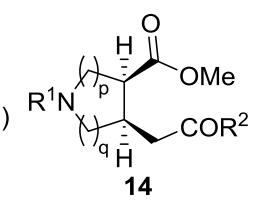

up to $99: 1$ er

Scheme 2. Isothiourea-catalyzed Michael addition-lactonization

To address these current deficiencies within (C1)-ammonium enolate catalysis, we sought to apply a Michael additionlactonization strategy for the synthesis of novel nitrogencontaining heterocycles. Based on our recent work detailing the synthesis of cis-chromenone derivatives, ${ }^{[10 c]}$ it was believed that 6-exo-trig cyclization of enone-acids 15 could provide access to stereo-defined tetrahydroisoquinoline derivatives 16 (Scheme 3). ${ }^{[12]}$ Reported herein are studies towards these heterocycles, which resulted in the serendipitous discovery of a synthetic protocol to access novel indoline-cyclobutanone products 18, formed through an intramolecular [2+2] cycloaddition involving an in situ-generated ketene (Scheme 3 ).

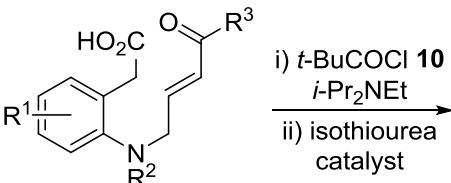

$$
\begin{aligned}
& 15 \\
& 4
\end{aligned}
$$

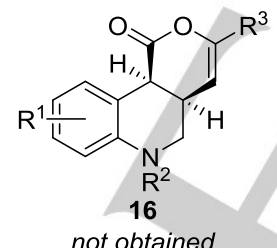

Scheme 3. Attempted isothiourea-catalyzed enantioselective synthesis of tetrahydroquinoline derivatives 16, and resulting discovery of process to access indoline-cyclobutanone derivatives 18

\section{Results and Discussion}

\section{Synthesis of Model Substrate and Reaction Optimization}

Initial studies focused on the development of a synthetic route to the requisite enone-acid substrates $15 . \mathrm{N}$-Allyl- $N$-tosylamine 19 could be accessed in three steps from commercially-available aminoalcohol 20 in $72 \%$ overall yield. ${ }^{[13]}$ Subjecting 20 to an ozonolysis/Wittig olefination sequence did not lead to the expected enone, with enamide $\mathbf{2 1}$ instead isolated as a $88: 12$ ratio of $(E)$ - and $(Z)$-isomers. ${ }^{[14]}$ The use of lower reaction

temperatures and shorter reaction times, in addition to an analogous Horner-Wadsworth-Emmons approach, also did not provide selective formation of the desired enone. An alkene cross-metathesis between $\mathrm{N}$-allyl- $\mathrm{N}$-tosylamine $\mathbf{2 0}$ and methyl vinyl ketone using Grubbs $2^{\text {nd }}$ generation catalyst was also attempted, but no enone was observed and only starting material recovered.

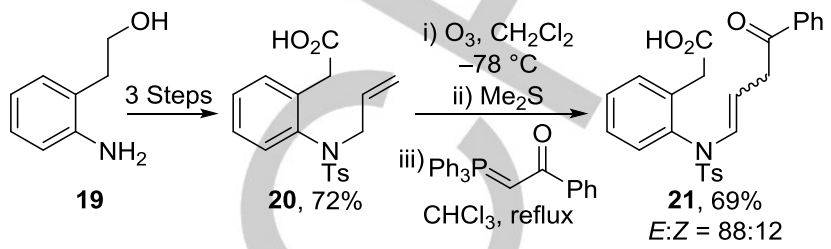

Scheme 4. Substrate synthesis

Despite the difficulties identified in accessing the desired enone substrate, it was reasoned that the basic conditions used in isothiourea-catalyzed Michael addition-lactonization may promote tautomerization of enamide $\mathbf{2 1}$ to the desired enone in situ. Accordingly, enamide $\mathbf{2 1}$ was treated with pivaloyl chloride 10 and $i-\mathrm{Pr}_{2} \mathrm{NEt}$ in $\mathrm{CHCl}_{3}$ at room temperature for 15 minutes, followed by the addition of tetramisole $\cdot \mathrm{HCl} 11$ and additional $i$ $\mathrm{Pr}_{2} \mathrm{NEt}$ (Scheme 5). Formation of the expected tetrahydroquinoline was not observed, with the only isolable product identified as fused indoline-cyclobutanone derivative $\mathbf{2 2}$ by single crystal $\mathrm{X}$-ray crystallographic analysis. ${ }^{[15]}$ Indoline derivative 22 was isolated in $42 \%$ yield as a single diastereoisomer, but HPLC analysis using a chiral support confirmed it was obtained as a racemate (entry 1). In an attempt to promote enantioselectivity, $20 \mathrm{~mol} \%$ of tetramisole $\cdot \mathrm{HCl} 11$ was added at the outset of the reaction, however indoline derivative $\mathbf{2 2}$ was still obtained as a racemate (entry 2). These resulted indicated that enantioinduction may be challenging, and therefore the use of simple achiral Lewis bases was investigated. Using either 4-dimethylaminopyridine (DMAP) or 1,4diazabicyclo[2.2.2]octane (DABCO) provided comparable yields of $( \pm)-22(42-43 \%$, entries 3 and 4$)$. Finally, the use of only pivaloyl chloride and $i-\mathrm{Pr}_{2} \mathrm{NEt}$, in the absence of an additional Lewis base catalyst, gave ( \pm )-22 in $46 \%$ yield (entry 5 ).

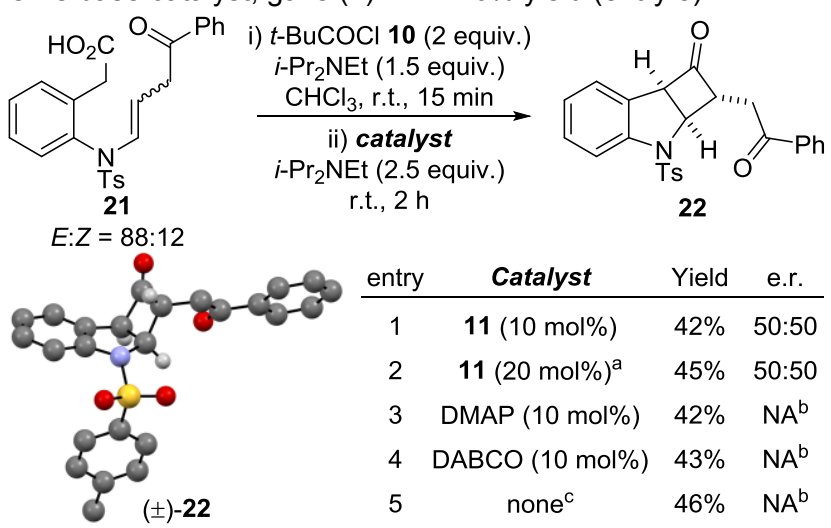

Scheme 5. Unexpected formation of indoline-cyclobutanone fused product 22, and representation of structure based on single crystal X-ray crystallographic analysis. Majority of hydrogen atoms omitted for clarity. ${ }^{a} \mathbf{1 1}$ added at start of reaction. ${ }^{b}$ not applicable. ${ }^{c} i$ - $\operatorname{Pr}_{2} \mathrm{NEt}$ ( 2 equiv.), $t$-BuCOCl 10 (2 equiv.), r.t., $2 \mathrm{~h}$. 
Although unexpected, both the mechanism of formation and the $3 \mathrm{D}$ structure of this heterocyclic product were intriguing. A survey of the literature revealed that although fused indoline ring systems are common within natural products and bioactive compounds, ${ }^{[16]}$ very few examples of indoline derivatives fused to 4 -membered rings have been reported. ${ }^{[17]}$ Considering the importance of developing methods that provide access to novel heterocyclic ring systems ${ }^{[1 b, c]}$ further studies into the formation of these fused indoline-cyclobutanone derivatives were pursued.

\section{Reaction Scope and Limitations}

The scope and limitations of this method for accessing novel fused indoline ring systems was investigated. The enamide substrates were prone to hydrolysis upon purification or storage, and were therefore used immediately after preparation (see Scheme 4 for synthetic approach). ${ }^{[13]}$ The scope of the synthetic process was first studied using enamide-acid substrates bearing different pendant ketones (Table 1). The introduction of either electron-withdrawing or -donating groups on the aryl ketone was tolerated, with products 23-26 obtained in moderate to good yield (38-64\%). ${ }^{[18]}$ The method was equally effective for alkylsubstituted ketones, with 27 obtained in 53\% yield, however changing the ketone to an ester resulted in a complex mixture of products. Changing the $\mathrm{N}$-substituent to $\mathrm{N}$-mesyl was also well tolerated, giving product $\mathbf{2 8}$ in $57 \%$ yield. Substitution on the indoline core of the products was next studied, with both electron-withdrawing 5-Cl and electron-donating 6-OMe groups incorporated to give products 29 and $\mathbf{3 0}$ in good yield (46-50\%). In all examples, analysis of the crude reaction product mixture by ${ }^{1} \mathrm{H}$ NMR spectroscopy revealed the formation of a number of minor side products; however none of these were successfully isolated or characterized. In each case only a single diastereoisomer was isolated, with products 24, 29 and 30 also characterized by single crystal X-ray crystallographic analysis, confirming the same relative configuration within each product. $^{[19,20]}$

\section{Proposed Mechanism}

Further studies sought to obtain insight into the mechanism of this reaction. The synthesis of related fused ring systems has been reported in the literature through purported [2+2] cycloadditions via transient ketene intermediates. ${ }^{[1]}$ In the majority of these examples dehydrochlorination of an acid chloride was utilized to generate the ketene in situ, followed by cycloaddition to a pendant alkene to give carbocyclic and oxygen-containing heterocyclic ring systems. Interception of a similar mechanistic pathway could be envisaged in the current study through base-promoted elimination of pivalic acid from the in situ-generated mixed anhydride 31 (Scheme 6, Path A). ${ }^{[22]}$ This mechanism would be of particular interest considering previous reports that suggest $\mathrm{C}(1)$-ammonium enolate catalysis most likely proceeds without the intermediacy of a ketene (see Scheme 1b). ${ }^{[23]}$ However, based on the relative nucleophilicity of the pendant enamide, an ionic mechanism, either via ketene 32 (Scheme 6, Path B), ${ }^{[24]}$ or through direct intramolecular addition of the enamide to the mixed anhydride (Scheme 6, Path C), ${ }^{[25]}$ could also be considered. All these pathways could also be initiated in the presence of a Lewis basic amine by conversion of
Table 1. Substrate Scope.
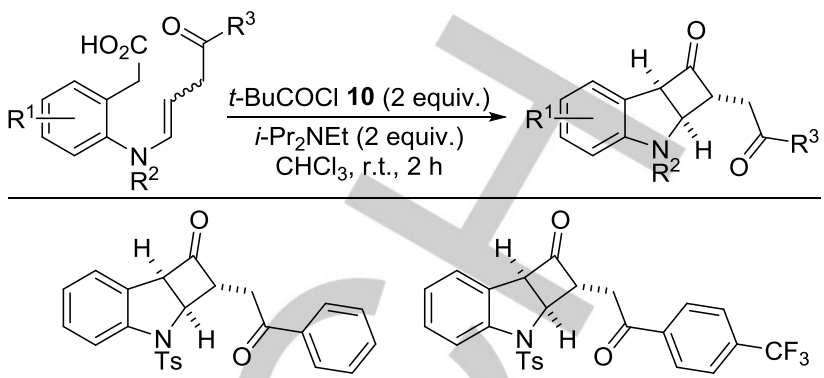

(土)-22, $46 \%$

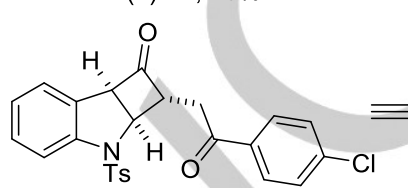

$( \pm)-24,57 \%$

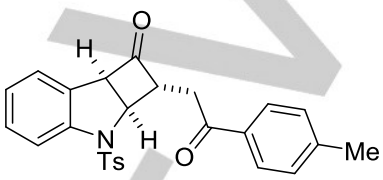

$( \pm)-25,64 \%$

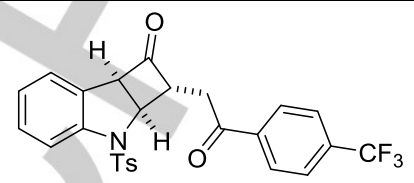

$( \pm)-23,38 \%$
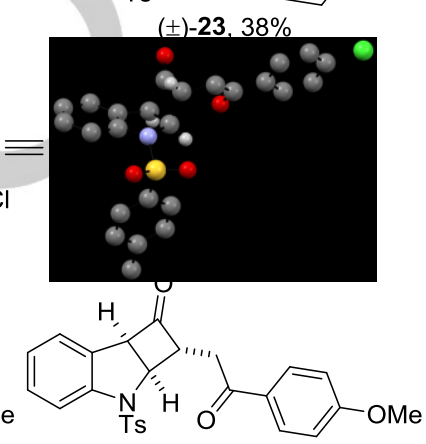

$( \pm)-26,42 \%$

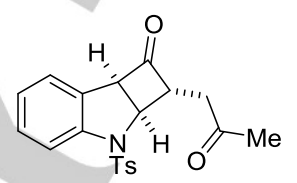

$( \pm)-27,53 \%$
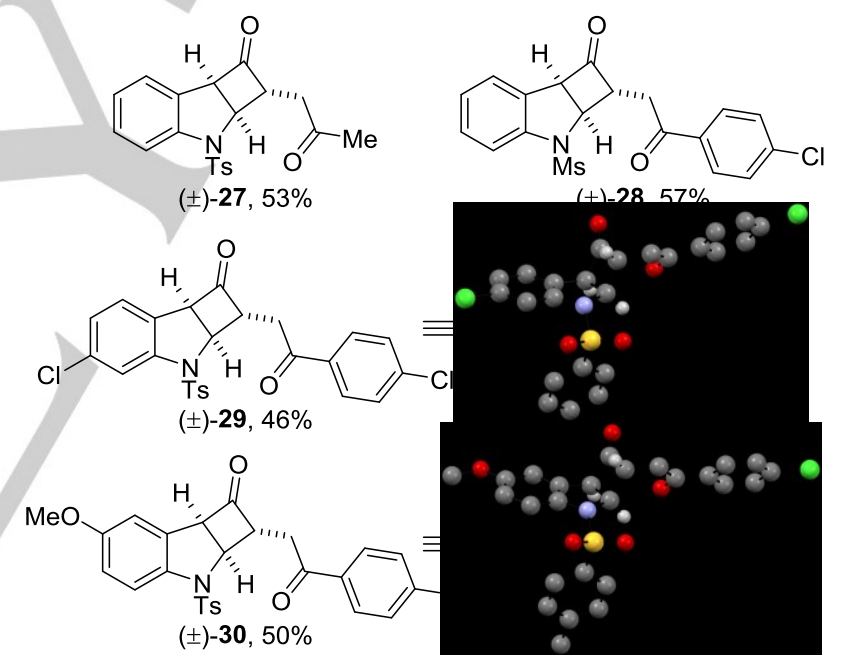

$+1.28 \quad 57 \%$

Yields calculated using mass of partially-purified enamide substrate used. Structure representations of $\mathbf{2 4}, \mathbf{2 9}$ and $\mathbf{3 0}$ based on single crystal X-ray crystallographic analysis. Majority of hydrogen atoms omitted for clarity.

the mixed anhydride to an acyl ammonium. ${ }^{[26]}$ In pathways $B$ and $\mathrm{C}$, the final cyclization could be classified as 4-enolendo-exo-trig, which would be disfavored according to Baldwin's rules. ${ }^{[27]}$ However formally-disfavored enolendo-cyclizations have been proposed when zwitterionic intermediates are involved, ${ }^{[28]}$ and therefore cannot be completely ruled out as a possibility in this case. 


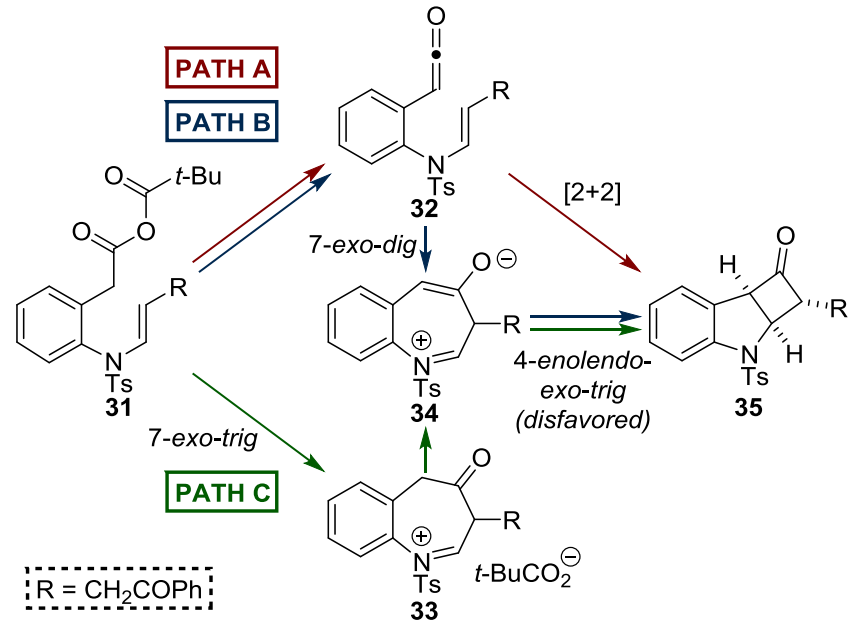

Scheme 6. Possible mechanistic pathways for the formation of indolinecyclobutanone fused products 35 in the presence of $i-\mathrm{Pr}_{2} \mathrm{NEt}$.

To provide insight into the potential for ketene generation, a model substrate $\mathbf{3 6}$, bearing an unactivated alkene, was applied under the standard conditions (Scheme 7). Reaction progress at room temperature was monitored by ${ }^{1} \mathrm{H}$ NMR spectroscopy. Within two hours, 55\% conversion to known cyclobutanone $\mathbf{3 7}$ was observed, ${ }^{[29]}$ indicative of a [2+2] cycloaddition mechanism involving a ketene. Although the alternate pathways cannot be fully discounted for the formation of the indoline-cyclobutanone fused products, this experiment does indicate the feasibility of Path A. This demonstration of ketene formation from a phenylacetic anhydride derivative at room temperature, in the presence of pivaloyl chloride and $i-\mathrm{Pr}_{2} \mathrm{NEt}$, also provides instructive insight for practitioners of $\mathrm{C}(1)$-ammonium enolate catalysis. ${ }^{[23,26]}$
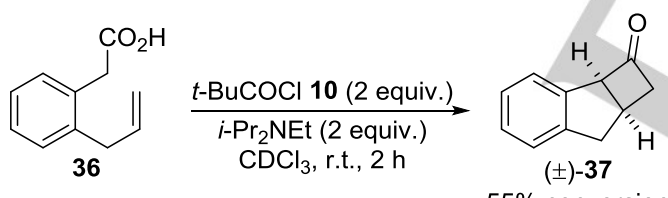

$55 \%$ conversion

Scheme 7. Mechanistic probe for in situ generation of a ketene intermediate

Based on these studies, and the lack of enantioinduction in the presence of a chiral Lewis base catalyst, a mechanism for the formation of these novel indoline-cyclobutanone products can be proposed (Scheme 8). Reaction of the acid substrate $\mathbf{3 8}$ with pivaloyl chloride and $i-\mathrm{Pr}_{2} \mathrm{NEt}$ provides mixed anhydride 39 , which undergoes $i-\mathrm{Pr}_{2} \mathrm{NEt}$-promoted elimination of pivalic acid to give ketene 40. Intramolecular [2+2] cycloaddition between the ketene and the pendant enamide then provides indolinecyclobutanone 41. The relative configuration of the isolated product is consistent with diastereospecific [2+2] cycloaddition involving only the $(E)$-enamide substrate. The $(Z)$-enamide may isomerize or decompose under the reaction conditions, the latter of which could partially account for the generally moderate yields obtained. Alternatively the (Z)-enamide may undergo diastereospecific [2+2] cycloaddition to give a diastereoisomer of the product that differs in configuration at the $\mathrm{C}(2)$ position. While this diastereoisomer was not observed, it may simply not have been isolable, or may have undergone epimerization at $\mathrm{C}(2)$ to give the isolated diastereoisomer $\mathbf{4 1 .}$

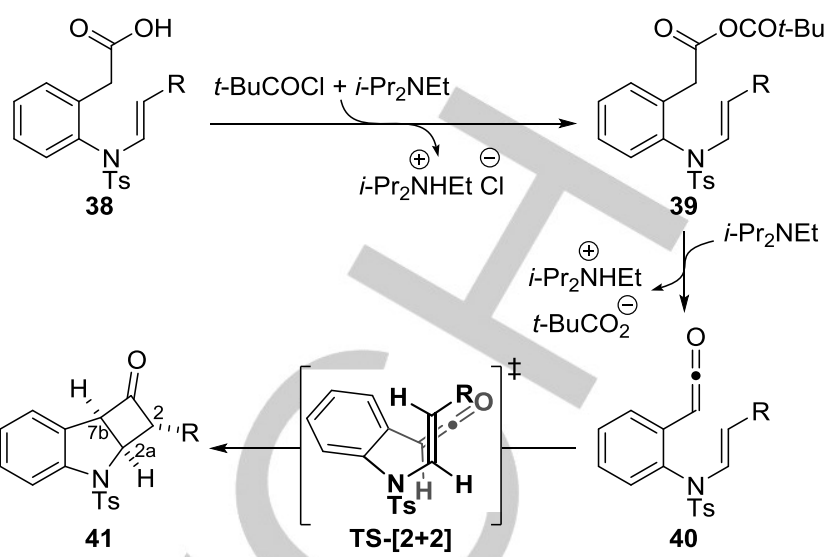

Scheme 8. Proposed mechanism for the formation of indoline-cyclobutanone fused products

\section{Conclusions}

During investigations into a tertiary amine-catalyzed cyclization, an unexpected process for generating novel indolinecyclobutanone derivatives was discovered serendipitously. This intramolecular process was applicable for the diastereoselective formation of a range of novel heterocyclic products, which may prove useful intermediates in natural product synthesis or the discovery of bioactive compounds. Based on literature precedents and mechanistic investigations, the reaction is proposed to proceed by an intramolecular [2+2] cycloaddition involving an in situ generated ketene. Evidence for the formation of a ketene from a mixed anhydride at room temperature highlights the importance of remaining cognizant of this reactive intermediate when developing enantioselective Lewis basecatalyzed processes. ${ }^{[30]}$

\section{Acknowledgments}

We thank the EPSRC Centre for Doctoral Training in Critical Resource Catalysis (CRITICAT, grant code EP/L016419/1, R.M.N.) for funding. We thank the European Research Council under the European Union's Seventh Framework Programme (FP7/2007-2013) ERC grant agreement no. 279850 (A.D.S.). A.D.S. thanks the Royal Society for a Wolfson Research Merit Award. We also thank the EPSRC UK National Mass Spectrometry Service at Swansea.

Keywords: Lewis base catalysis $\cdot$ ketene $\cdot[2+2]$-cycloaddition $\bullet$ $\mathrm{N}$-heterocycles $\bullet$ indoline-cyclobutanone

[1] a) J. A. Joule, Adv. Heterocycl. Chem., 2016, 119, 81-106; b) E. Vitaku, D. T. Smith, J. T. Njardarson, J. Med. Chem., 2014, 57, 10257-10274 C) R. D. Taylor, M. MacCoss, A. D. G. Lawson, J. Med. Chem., 2014, 57, 5845-5859; d) D. C. Blakemore, L. Castro, I. Churcher, D. C. Rees, A. W. Thomas, D. M. Wilson, A. Wood, Nat. Chem., 2018, 10, 383-394; e) C. Lamberth, Pest Manag. Sci., 2013, 69, 1106-1114.

[2] a) F. Lovering, J. Bikker, C. Humblet, J. Med. Chem., 2009, 52, 67526756; b) F. Lovering, Med. Chem. Commun., 2013, 4, 515-519. 
[3] a) K. N. Van, L. C. Morrill, A. D. Smith, D. Romo in Lewis Base Catalysis in Organic Synthesis, Vol. 2 (Eds.: E. Vedejs, S. E. Denmark), Wiley-VCH, Weinheim, 2016, ch. 13, pp. 527-653; b) M. J. Gaunt, C. C C. Johansson, Chem. Rev., 2007, 107, 5596-5605.

[4] G. S. Cortez, R. L. Tennyson, D. Romo, J. Am. Chem. Soc., 2001, 123, 7945-7946.

[5] T. Mukaiyama, U. Masahiro, S. Eiichiro, S. Kazuhiko, Chem. Lett., 1975, 4, 1045-1048

[6] a) W. T. Brady, Y.-S. F. Giang, A. P. Marchand, A.-H. Wu, J. Org. Chem., 1987, 52, 3457-3461; b) R. L. Funk, M. M. Abelman, K. M Jellison, Synlett, 1989, 36-37.

[7] a) S. H. Oh, G. S. Cortez, D. Romo, J. Org. Chem., 2005, 70, 2835 2838; b) V. C. Purohit, A. S. Matla, D. Romo, J. Am. Chem. Soc., 2008 130, 10478-10479; c) C. A. Leverett, V. C. Purohit, D. Romo, Angew. Chem. Int. Ed., 2010, 49, 9479-9483; Angew. Chem., 2010, 122 9669-9673; d) K. A. Morris, K. M. Arendt, S. H. Oh, D. Romo, Org. Lett., 2010, 12, 3764-3767; e) G. Liu, M. E. Shirley, D. Romo, J. Org. Chem., 2012, 77, 2496-2500.

[8] a) H. Henry-Riyad, C. Lee, V. C. Purohit, D. Romo, Org. Lett., 2006, 8, 4363-4366; b) G. Ma, H. Nguyen, D. Romo, Org. Lett., 2007, 9, 21432146; c) W. Zhang, A. S. Matla, D. Romo, Org. Lett., 2007, 9, 21112114; d) H. Nguyen, G. Ma, D. Romo, Chem. Commun., 2010, 46 4803-4805; e) G. Liu, D. Romo, Angew. Chem. Int. Ed., 2011, 50 7537-7540; Angew. Chem., 2011, 123, 7679-7682; f) Y. Feng, M. M. Majireck, S. M. Weinreb, Angew. Chem. Int. Ed., 2012, 51, 12846 12849; Angew. Chem., 2012, 124, 13018-13021; g) C. A. Leverett, V. C. Purohit, A. G. Johnson, R. L. Davis, D. J. Tantillo, D. Romo, J. Am Chem. Soc., 2012, 134, 13348-13356.

[9] a) D. Sikriwal, D. K. Dikshit, Tetrahedron, 2011, 67, 210-215; b) W. Kong, D. Romo, J. Org. Chem., 2017, 82, 13161-13170.

[10] a) D. Belmessieri, L. C. Morrill, C. Simal, A. M. Z. Slawin, A. D. Smith, J. Am. Chem. Soc., 2011, 133, 2714-2720; b) D. Belmessieri, A. de la Houpliere, E. D. D. Calder, J. E. Taylor, A. D. Smith, Chem. - Eur. J. 2014, 20, 9762-9769; c) R. M. Neyyappadath, D. B. Cordes, A. M. Z. Slawin, A. D. Smith, Chem. Commun., 2017, 53, 2555-2558.

[11] a) D. Belmessieri, D. B. Cordes, A. M. Z. Slawin, A. D. Smith, Org. Lett., 2013, 15, 3472-3475; b) D. G. Stark, P. Williamson, E. R. Gayner, S. F. Musolino, R. W. F. Kerr, J. E. Taylor, A. M. Z. Slawin, T. J. C. O'Riordan, S. A. Macgregor, A. D. Smith, Org. Biomol. Chem., 2016, 14, 8957-8965.

[12] V. Sridharan, P. A. Suryavanshi, J. C. Menéndez, Chem. Rev., 2011, 111, 7157-7259.

[13] See Supporting Information for more details.

[14] The ratio of $(E)$ - and $(Z)$-enamides obtained varied upon repeated synthesis and isolation (generally in range of $80: 20 \rightarrow 95: 5, E: Z$ ).

[15] Crystallographic data for 22 (CCDC 1898468) is available free of charge from The Cambridge Crystallographic Data Centre via www.ccdc.cam.ac.uk/structures.

[16] a) D. Zhang, H. Song, Y. Qin, Acc. Chem. Res., 2011, 44, 447-457; b) D. Liu, G. Zhao, L. Xiang, Eur. J. Org. Chem., 2010, 3975-3984; c) W. Zi, Z. Zuo, D. Ma, Acc. Chem. Res., 2015, 48, 702-711; d) M. S. Kirillova, F. M. Miloserdov, A. M. Echavarren, Org. Chem. Front., 2018, 5, 273-287.

[17] a) D. Julian, R. Foster, J. Chem. Soc. Chem. Commun., 1973, $311-$ 312; b) M. Ikeda, T. Uno, K.-I. Homma, K. Ohno, Y. Tamura, Synth. Commun., 1980, 10, 437-449; c) M. Ikeda, K. Ohno, S. Mohri, M. Takashi, Y. Tamura, J. Chem. Soc., Perkin Trans. 1, 1984, 405-412; d) K. Shishido, T. Azuma, M. Shibuya, Tetrahedron Lett., 1990, 31, 219220; e) D. J. Hastings, A. C. Weedon, Can. J. Chem., 1991, 69, 11711181 ; f) D. L. Oldroyd, A. C. Weedon, J. Org. Chem., 1994, 59, 13331343; g) M. I. Attia, D. Güclü, B. Hertlein, J. Julius, P. A. Witt-Enderby, D. P. Zlotos, Org. Biomol. Chem., 2007, 5, 2129-2137; h) T. Ozawa, M. Kanematsu, H. Yokoe, M. Yoshida, K. Shishido, J. Org. Chem., 2012 77, 9240-9249; i) T. Araki, T. Owawa, H. Yokoe, M. Kanematsu, M. Yoshida, K. Shishido, Org. Lett., 2013, 15, 200-203; j) T. Araki, Y.
Manabe, K. Fujioka, H. Yokoe, M. Kanematsu, M. Yoshida, K. Shishido, Tetrahedron Lett., 2013, 54, 1012-1014.

[18] The enamide substrates were not stable for long periods, and were therefore only quickly purified by silica column chromatography and dried under high vacuum for 15 minutes. These enamides were then applied in the subsequent reaction despite containing some minor impurities and residual solvent. The yields of indoline-cyclobutanone products reported are therefore most likely underestimated.

[19] Crystallographic data for 24 (CCDC 1898469) 29 (CCDC 1898470) and 30 (CCDC 1898471) is available free of charge from The Cambridge Crystallographic Data Centre via www.ccdc.cam.ac.uk/structures.

[20] The relative configurations of the remaining products were assigned by analogy.

[21] See references 6, 17d,h-j and: a) B. B. Snider, Chem. Rev., 1988, 88, 793-811; b) B. B. Snider, R. A. H. F. Hui, Y. S. Kulkarni, J. Am. Chem. Soc., 1985, 107, 2194-2196; c) Y. S. Kulkarni, B. W. Burbaum, B. B Snider, Tetrahedron Lett., 1985, 26, 5619-5622; d) I. Markó, B. Ronsmans, A.-M. Hesbain-Frisque, S. Dumas, L. Ghosez, J. Am. Chem. Soc., 1985, 107, 2192-2194; e) E. J. Corey, M. C. Desai, T. A. Engler, J. Am. Chem. Soc., 1985, 107, 4339-4341; f) M. Lachia, P. M. J. Jung, A. De Mesmaeker, Tetrahedron Lett., 2012, 53, 4514-4517.

[22] For reports that propose ketene generation from mixed anhydrides in the presence of base, see: a) J. J. Beereboom, J. Org. Chem., 1965, 30, 4230-4234; b) A. Corbella, P. Gariboldi, M. Gil-Quintero, G. Jommi, J. St. Pyrek, Experientia, 1977, 33, 703-704; c) W. T. Brady, A. P. Marchand, Y.-S. F. Giang, A.-H. Wu, Synthesis, 1987, 395-396; d) W T. Brady, Y.-Q. Gu, J. Heterocyclic Chem., 1988, 25, 969-971; e) T. Saito, T. Suzuki, M. Morimoto, C. Akiyama, T. Ochiai, K. Takeuchi, T. Matsumoto, K. Suzuki, J. Am. Chem. Soc., 1998, 120, 11633-11644; f) S. Serra, C. Fuganti, A. Moro, J. Org. Chem., 2001, 66, 7883-7888.

[23] For discussion on the potential of ketene generation from carboxylic acid-derived substrates in $\mathrm{C}(1)$-ammonium enolate catalysis see references 3a, 4, 7d, 8a,b and: T. H. West, D. M. Walden, J. E. Taylor A. C. Brueckner, R. C. Johnston, P. H.-Y. Cheong, G. C. Lloyd-Jones, A. D. Smith, J. Am. Chem. Soc., 2017, 139, 4366-4375.

[24] a) P. Otto, L. A. Feiler, R. Huisgen, Angew. Chem. Int. Ed., 1968, 7, 737-738; b) R. Huisgen, P. Otto, J. Am. Chem. Soc., 1968, 91, 59225923; c) K. Takaoka, T. Aoyama, T. Shioiri, Synlett, 1994, 1005-1006; d) A. R. de Faria, E. L. Salvador, C. R. D. Correia, J. Org. Chem., 2002, 67, 3651-3661; e) A. C. B. Montes de Oca, C. R. D. Correia, ARKIVOC, 2003, 390-403.

[25] M. A. Waly, Acta Chim. Slov., 2008, 55, 343-349.

[26] For discussion on the formation of ketenes from acyl ammonium intermediates see reference 22 e and: a) A. C. Spivey, S. Arseniyadis Angew. Chem. Int. Ed., 2004, 43, 5436-5441; Angew. Chem. Int. Ed. 2004, 116, 5552-5557; b) A. K. Sheinkman, S. I. Suminov, A. N. Kost Russ. Chem. Rev., 1973, 42, 642-661; c) A. C. Spivey, A. Maddaford D. P. Leese, A. J. Redgrave, J. Chem. Soc. Perkin Trans. 1, 2001 1785-1794; d) M. E. Abbasov, B. M. Hudson, D. J. Tantillo, D. Romo, Chem. Sci., 2017, 8, 1511-1524.

[27] a) J. E. Baldwin, J. Chem. Soc. Chem. Commun., 1976, 734-736; b) J. E. Baldwin, L. I. Kruse, J. Chem. Soc. Chem. Commun., 1977, 233235; c) J. E. Baldwin, M. J. Lusch, Tetrahedron, 1982, 38, 2939-2947; d) K. Gilmore, R. K. Mohamed, I. V. Alabugin, WIREs Comput. Mol. Sci., 2016, 6, 487-514.

[28] Excluding examples of electrocyclic reactions, see reference 24 and: a) B. M. Trost, T. A. Runge, J. Am. Chem. Soc., 1981, 103, 2485-2487; b) B. M. Trost, T. A. Runge, J. Am. Chem. Soc., 1981, 103, 7559-7572; c) N. A. Petasis, S.-P. Lu, J. Am. Chem. Soc., 1995, 117, 6394-6395; d) S. J. Meek, F. Pradaux, D. R. Carbery, E. H. Demont, J. P. A. Harrity, J. Org. Chem., 2005, 70, 10046-10056.

[29] For prior syntheses of $\mathbf{3 6}$ see reference $21 \mathrm{f}$ and: J. L. Scotson, B. I. Andrews, A. P. Laws, M. I. Page, Org. Biomol. Chem., 2016, 14, 83018308.

[30] The research data supporting this publication can be accessed at https://doi.org/10.17630/00aff760-0732-438f-a9d1-30c7cf3a87a0. 
Entry for the Table of Contents (Please choose one layout)

Layout 1:

\section{COMMUNICATION}

Text for Table of Contents (about 350 characters)
((Insert TOC Graphic here: max. width: $5.5 \mathrm{~cm}$; max. height: $5.0 \mathrm{~cm}$; NOTE: the final letter height should not be less than $2 \mathrm{~mm}$.))

\section{Key Topic*}

Author(s), Corresponding Author(s)*

Page No. - Page No.

Title 